\title{
Low Back Pain Severity and Related Disability in Different Trimesters of Pregnancy and Risk Factors
}

\author{
Maryam Rabiee $^{1^{*}(\mathbb{C}}$, Niloofar Sarchamie $^{2}$
}

\begin{abstract}
Objectives: Low back pain (LBP) is one of the most prevalent complications of pregnancy, which can cause significant disabilities. However, data on the intensity of and disability caused by LBP during pregnancy are rare. The purpose of this study was to evaluate the severity of and disability caused by LBP, and compare them in different trimesters, and identify risk factors.

Materials and Methods: This cross-sectional study was conducted in 2013 on 514 pregnant women. A questionnaire on demographic information, severity of LBP (based on VAS), and the Oswestry disability scale was filled out by the participants. Data were analysed by Mann-Whitney, one-way ANOVA, and linear regression using SPSS software. $P$ value below 0.05 was considered to be statistically significant.

Results: In total, $69.09 \%$ of participants had LBP. The mean severity of visual scale pain was $38.2 \pm 10.88$ and mean disability due to LBP was $35.38 \pm 18.30$. The highest severity of pain, attributed to the second trimester, was $40.8 \pm 21.7$ and the highest disability score, $37.13 \pm 18.81$, was observed in the third trimester. In total, $77.1 \%$ of pregnant women studied with LBP had moderate to severe disability. There were meaningful associations of gestational age, parity, and previous chronic LBP with disability due to LBP $(P$ value $<0.05)$.

Conclusions: LBP during pregnancy is very prevalent and causes moderate to severe disability in the majority of pregnant women. Keywords: Low back pain, Severity, Disability, Pregnancy
\end{abstract}

\section{Introduction}

Low back pain (LBP) is one of the most common and costly problems of women during pregnancy $(1,2)$. The incidence of LBP in the pregnant population is much further than it in the general non-pregnant population (3). In most studies, the occurrence of LBP during pregnancy has been stated to be as high as 50\% (range: 20\%-90\%) $(1,4,5)$. Despite this fact, the exact pathophysiology and aetiology have not been elucidated yet and factors such as increased fluid retention in interstitial tissues, hormonal changes, loosening of joint ligaments in pelvic girdle and vertebrae, position of foetus in front of vertebral column and pelvic girdle, increase in mother's weight, and increased lumbar lordosis have been reported as possible underlying reasons for LBP in pregnancy $(6,7)$. However, some suggest that pain during pregnancy cannot be described by biomechanical factors alone; psychosocial factors seem to be important as well. Low back and pelvic disorders throughout the course of gestation are considered a major public health issue (8). Pregnancyrelated LBP can decrease the capability of women to do their ordinary work and lead to significant reduction in women's quality of life (8-10). LBP is the reason for $68 \%$ of absence from work and $22 \%$ of maternity leave $(9,11)$. In some women, LBP has been reported till 2-3 years after gestation and some women indicated pregnancy as the main underlying cause of chronic LBP $(9,12)$. Disability is described as a limitation in daily activities such as walking, sitting, lifting objects, social life, personal tasks, professional work, and even sleeping or travelling (13). Though many investigations have been performed on the occurrence of LBP in pregnant women and its underlying factors, only a few studies have assessed the severity of pregnancy-related LBP and its associated disability. Still, it is not possible to predict which pregnant women would develop greater LBP and more disability than others.

Previous studies were mostly performed on women in the third trimester with higher prevalence of LBP, but this study recruited participants from all three trimesters to assess the frequency and severity of and disability due to LBP. This was one of the rare studies in Iran that assessed disabilities due to LBP in pregnancy and the underlying factors, in order to provide information for improving quality of life in pregnant women.

\section{Materials and Methods}

This cross-sectional study was conducted in Obstetrics Clinic of Mostafa Khomeini Teaching hospital in Tehran, on 514 participants including 98 in the first trimester, 145 in the second trimester, and 271 in the third trimester 
of pregnancy. Women with a history of herniated disc, trauma, previous surgery in the lumbar vertebrae, vertebral column deformities such as scoliosis, and inflammatory disorders of vertebrae were excluded from this study. Each participant filled in written informed consent form. Each participant filled in a questionnaire about the current presence of LBP, obstetric history, demographic, and general health. LBP was recognized using a pain drawing completed by each participant. On the subject of current LBP, additional information was gathered on the severity and disability by visual analogue scale (VAS) and Oswestry Disability Index (ODI) questionnaire, respectively. VAS is an acceptable method for clinical researchers to assess clinical pain. This tool is a $10-\mathrm{cm}$ scale numbered from 0 to 100 . Zero indicates no pain and 100 is the most severe pain experienced. Zero to $20 \mathrm{~mm}$ indicates low pain, $20-40 \mathrm{~mm}$ is moderate pain, $40-60 \mathrm{~mm}$ is severe pain, $60-80 \mathrm{~mm}$ is very severe pain, and $80-100 \mathrm{~mm}$ is totally intolerable pain. Pregnant women were asked to mark their pain on this scale. The ODI is used to assess disability due to LBP and its adverse effects on daily activities. The participants were asked 10 questions about pain severity and their ability to do personal activities like lifting objects, walking, sitting, standing, sleeping, social activities, travelling, job, and house tasks. Answers ranged from 0 to 5 . Total score was calculated from 50 as ODI. For easier understanding, ODI was split into 5 groups: mild, moderate, severe, very severe, and totally disabling. In this study, the second version of ODI was used, which was translated into the Persian language by Mousavi et al in 2006; its relativity and reliability have been verified for Persian-speaking individuals (14). SPSS was used to analyse the data. Mann-Whitney, Spearman correlation coefficient, and linear logistic regression were used to assess the factors related with pain severity and disability. $P$ value below 0.05 was considered to be statistically significant.

\section{Results}

The mean age of the pregnant women studied was $28.98 \pm$ 5.02 years, ranging from 16 to 43 years. Other demographic characteristics of subjects are shown in Table 1. Among the 514 participants, $98(19.1 \%)$ were in their first trimester, $145(28.2 \%)$ in their second trimester, and 271 (52.7\%) in their third trimester. A total of 355 (69.06\%) participants had LBP. Further, 62 of 98 (63.3\%) women in the first trimester, 92 of $145(63.4 \%)$ in the second trimester, and

Table 1. Demographic characteristics of the study population

\begin{tabular}{lcc}
\hline Variable & Mean & Range \\
\hline Mother age $(\mathrm{y})$ & $28.98 \pm 5.02$ & $16-43$ \\
Gestational age $(\mathrm{wk})$ & $25.98 \pm 10.24$ & $4-40$ \\
BMI & $29.07 \pm 4.72$ & $17.5-58.96$ \\
Gravidity number & $1.65 \pm 0.56$ & $1-4$ \\
Parity number & $0.83 \pm 0.73$ & $0-3$ \\
\hline
\end{tabular}

201 of $271(74.2 \%)$ in the third trimester had LBP. The prevalence of LBP in the three trimesters was significantly different $(P=0.03)$.

Mean pain severity (VAS) was $38.2 \pm 18.8 \mathrm{~mm}$. Mean pain severity was $36.2 \pm 17.2 \mathrm{~mm}$ in the first trimester, 40.8 $\pm 21.7 \mathrm{~mm}$ in the second trimester, and $37.3 \pm 17.7 \mathrm{~mm}$ in the third trimester (Figure 1), although these differences were not meaningful $(P=0.62)$. Significant correlation between pain severity and gestational age $(P=0.01)$, and between pain severity and previous history of LBP $(P=0.001)$ were detected (Figure 1 ; Table 2); but linear regression demonstrated that the most important factor influencing the severity of pain in LBP was gestational age (odds ratio [OR] 0.012; CI 95\%: -0.008-0.032; $P=$ $0.000)$. Women with previous history of LBP had more VAS compared to those without it by 10.32 , though this correlation was not significant (OR 1.032; CI 95\%: 0.5851.480; $P=0.229)$.

Overall, mean disability score in participants was 35.38 \pm 18.3 ; however, it was $30.08 \pm 15.92$ in the first trimester, $34.79 \pm 18.13$ in the second trimester, and $37.13 \pm 18.81$ in the third trimester. A meaningful difference was detected in terms of disability due to LBP in the three trimesters $(P=0.029)$, and there was a linear tendency between disability and gestational age (Figure 2). According to the Tukey test, pairwise comparisons of the trimesters showed that average trimester ODI in the first trimester was significantly different from that in the third trimester $(P=0.023)$.

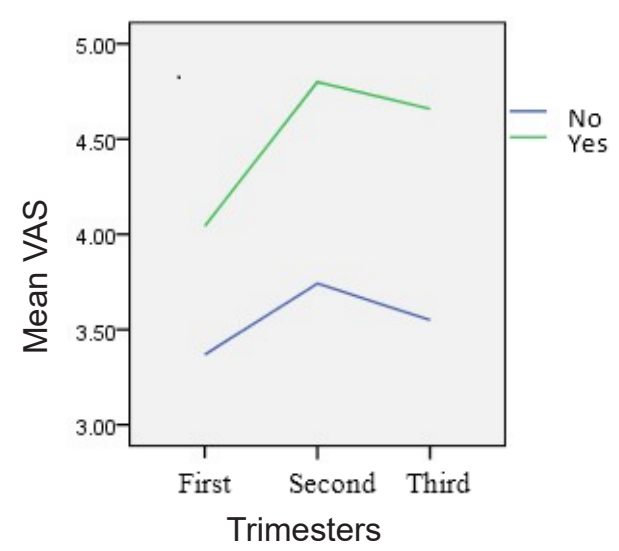

Figure 1. Mean Visual Analogue Scale in the 3 Trimesters of Pregnant Women With and Without Prior Low Back Pain.

Table 2. Disability Caused by Low Back Pain in the 3 Trimesters

\begin{tabular}{lccc}
\hline Disability & 1st Trimester & 2nd Trimester & 3rd Trimester \\
\hline Mild & $18(31 \%)$ & $20(23.3 \%)$ & $37(20.1 \%)$ \\
Moderate & $26(44.8 \%)$ & $38(44.2 \%)$ & $80(43.5 \%)$ \\
Severe & $12(20.7 \%)$ & $20(23.3 \%)$ & $44(23.9 \%)$ \\
Very severe & $2(3.4 \%)$ & $6(7 \%)$ & $19(10.3 \%)$ \\
Total disability & $0(0 \%)$ & $2(2.3 \%)$ & $4(2.2 \%)$ \\
Total & 62 & 86 & 184 \\
\hline
\end{tabular}




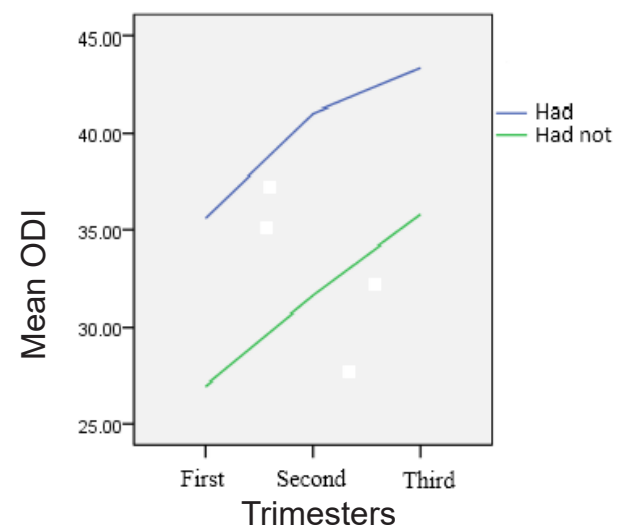

Figure 2. Mean Oswestry Disability Index in the 3 Trimesters in Pregnant Women With and Without Prior Low Back Pain.

In total, 328 of 355 mothers completed the disability questionnaire, from which, 75 (22.86\%) had mild disability, 144 (43.90\%) moderate disability, 76 (23.17\%) severe disability, $27(8.23 \%)$ very severe disability, and $6(0.018 \%)$ total disability. Hence, most of them had moderate disability during pregnancy (Table 2).

In this study, the effect of some factors such as the participants' age, gestational age, body mass index, gravidity and delivery, delivery method and use of anaesthesia in previous pregnancies, job status, and exercise during pregnancy were assessed with regard to pain severity and disability in the pregnant women with LBP. This relationship is shown in Table 3. Linear regression was used. Results of linear regression regarding ODI are presented in Table 4.

As shown in Table 4, previous history of LBP, parity, and gestational age were the most important factors influencing disability due to LBP in this study.

With an increase in gestational age every week, ODI increased by 0.38 . However, ODI was higher by 7.88 in the women with previous history of chronic LBP compared to those without it. By each parity, ODI increased by 7.06.

\section{Discussion}

This study was conducted to assess the pain severity and disability related to LBP in each trimester of pregnancy. In this study, $69.06 \%$ of pregnant women had LBP. The prevalence of LBP in three trimesters was significantly different. Mean score of pain (VAS) was moderate. The maximum VAS was observed in the second trimester of pregnancy; however, pain severity was not meaningfully different in the trimesters. There was a meaningful

Table 3. Association of Variables With Pain Severity (Visual Analogue Scale) and Disability Due to Low Back Pain (Oswestry Disability Index)

\begin{tabular}{|c|c|c|c|c|}
\hline Variable & VAS Mean & $P$ Value & ODI Mean & $P$-value \\
\hline $\begin{array}{l}\text { Mother age }(y) \\
\text { Below } 20 \\
21-26 \\
27-33\end{array}$ & $\begin{array}{l}31.33 \pm 15.52 \\
37.55 \pm 16.91 \\
38.96 \pm 20.41\end{array}$ & $\begin{array}{l}0.38 \\
\text { Spearman correlation }\end{array}$ & $\begin{array}{l}28.21 \pm 16.24 \\
31.25 \pm 16.39 \\
36.97 \pm 19.30\end{array}$ & $\begin{array}{l}0.005 \\
R=0.15\end{array}$ \\
\hline Gestational age & & $\leq 0.01$ & & $\leq 0.01$ \\
\hline $\begin{array}{l}\text { BMI } \\
\text { Below } 20 \\
20-25 \\
25-30 \\
\text { More than } 30\end{array}$ & $\begin{array}{l}25.0 \pm 10.0 \\
40.85 \pm 18.74 \\
38.95 \pm 19.93 \\
38.08 \pm 18.95\end{array}$ & $\begin{array}{l}0.43 \\
\text { Spearman correlation }\end{array}$ & $\begin{array}{l}10.0 \pm 4.33 \\
32.84 \pm 18.68 \\
36.4 \pm 17.26 \\
37.98 \pm 19.70\end{array}$ & $\begin{array}{l}0.037 \\
\text { One-way ANOVA }\end{array}$ \\
\hline $\begin{array}{l}\text { Gravidity number } \\
1 \\
2 \\
3\end{array}$ & $\begin{array}{l}30.7 \pm 18.1 \\
40 \pm 19.2 \\
40.2 \pm 21.8\end{array}$ & $\begin{array}{l}0.17 \\
\text { Spearman correlation }\end{array}$ & $\begin{array}{l}31.91 \pm 15.89 \\
37.99 \pm 19 \\
41.46 \pm 21.68\end{array}$ & $\begin{array}{l}0.01 \\
R=0.18\end{array}$ \\
\hline $\begin{array}{l}\text { Parity number } \\
0 \\
1 \\
2 \\
3\end{array}$ & $\begin{array}{l}36.7 \pm 18.0 \\
40.4 \pm 19.5 \\
38.7 \pm 20.7 \\
38.5 \pm 19.5\end{array}$ & $\begin{array}{l}0.16 \\
\text { Spearman correlation }\end{array}$ & $\begin{array}{l}31.91 \pm 15.89 \\
37.99 \pm 19 \\
41.46 \pm 21.68 \\
42.88 \pm 23.80\end{array}$ & $\begin{array}{l}0.008 \\
R=0.14\end{array}$ \\
\hline $\begin{array}{l}\text { Previous method of delivery } \\
\text { Natural vaginal delivery } \\
\text { Cesarean section }\end{array}$ & $\begin{array}{l}43.9 \pm 22.3 \\
39.2 \pm 18.5\end{array}$ & $\begin{array}{l}0.43 \\
\text { Mann-Whitney }\end{array}$ & $\begin{array}{l}40.79 \pm 25.04 \\
38.36 \pm 17.5\end{array}$ & $\begin{array}{l}0.57 \\
t \text { test }\end{array}$ \\
\hline $\begin{array}{l}\text { Anesthesia } \\
\text { General } \\
\text { Local }\end{array}$ & $\begin{array}{l}36.4 \pm 17.1 \\
41.6 \pm 19.4\end{array}$ & $\begin{array}{l}0.116 \\
\text { Mann-Whitney }\end{array}$ & $\begin{array}{l}38.26 \pm 19.89 \\
38.44 \pm 15.64\end{array}$ & $\begin{array}{l}0.95 \\
t \text { test }\end{array}$ \\
\hline $\begin{array}{l}\text { Job status } \\
\text { Worker } \\
\text { Housewife }\end{array}$ & $\begin{array}{l}38.9 \pm 18.7 \\
38.0 \pm 18.9\end{array}$ & $\begin{array}{l}0.6 \\
\text { Mann-Whitney }\end{array}$ & $\begin{array}{l}33.18 \pm 17.91 \\
36.85 \pm 18.47\end{array}$ & $\begin{array}{l}0.74 \\
t \text { test }\end{array}$ \\
\hline $\begin{array}{l}\text { Exercise in pregnancy } \\
\text { Yes } \\
\text { No }\end{array}$ & $\begin{array}{l}39.0 \pm 19.3 \\
37.6 \pm 18.5\end{array}$ & $\begin{array}{l}0.6 \\
\text { Mann-Whitney }\end{array}$ & $\begin{array}{l}33.18 \pm 17.91 \\
36.85 \pm 18.47\end{array}$ & $\begin{array}{l}0.74 \\
\text { Mann-Whitney }\end{array}$ \\
\hline
\end{tabular}


Table 4. Linear Regression Analysis of Factors Associated With Disability (Oswestry Disability Index)

\begin{tabular}{llll}
\hline Variable & P value & 95\% Cl & OR \\
\hline Mother's age & 0.700 & $-0.405-0.602$ & 0.099 \\
Gestational age & 0.001 & $0.157-0.613$ & 0.385 \\
BMI & 0.394 & $-0.273-0.691$ & 0.209 \\
Parity & 0.032 & $0.597-13.535$ & 7.066 \\
Delivery frequency & 0.159 & $-13.007-2.143$ & -5.432 \\
Previous chronic LBP & 0.001 & $3.164-12.615$ & 7.889 \\
LBP in previous pregnancy & 0.593 & $-2.227-3.888$ & 0.830 \\
\hline
\end{tabular}

Abbreviations: BMI, body mass index; OR, odds ratio; LBP, Low back pain

difference between the 3 trimesters with regard to mean disability score. Disability increased with gestational age, and the maximum disability (ODI) was seen in the third trimester of pregnancy. Most women who suffered from LBP had moderate disability, while $32 \%$ of them had severe to total disability. However, the prevalence of LBP in the pregnant women was much higher than that in the general non-pregnant population. Almost all previous investigations indicate a high prevalence of pregnancyrelated LBP $(1,3,5,6)$. In a research, it was reported that $58 \%$ of Canadian women and $83 \%$ of Beninese women complained of back pain during pregnancy (13). A period outbreak of $72 \%$ was reported by a study conducted on pregnant Japanese women above 36 weeks (15). Moreover, in studies done on Iranian women, like this research, LBP was reported from most pregnant women $(64 \%)(1,16)$. One of the important impacts of back pain is its effect on daily activity and ability.

Pregnancy-dependent back or pelvic girdle pain can decrease the ability of women to do their regular work (13).

In this study, the mean score of pain intensity (VAS) and disability was moderate, in accordance with the results of some of the other studies. One of the few studies done in Iran was that by Mohsenie-Bandpei et al on LBP in pregnant Iranian women. In their study, mean disability score was found to be moderate but mean intensity of pain was severe (1). In the investigation by Adair et al, $24 \%-57 \%$ of the participants had at least a moderate level of disability (17). Another study compared the pain intensity and disability due to LBP during pregnancy and living situation in Canadian and Beninese pregnant women, and concluded that the scores from both groups corresponded with moderate to severe disability. Although a greater percentage of Beninese women announced severe disability (13), these results were consistent with our results. Another study by Madeira et al in Portugal assessed 269 women; the disability score of most were mild to moderate (18). In the studies by Pierce et al and Mens et al, severity of pain and disability score were mild in most pregnant women $(3,19)$. To justify this difference, it should be considered that perception, pain experience, beliefs, and viewpoints towards pain may differ across cultures and nations and affect the reported disability and severity of pain. An important result of our study was that more than half of the participants suffered from a reduced ability to perform their daily chores. Some researchers have shown that this reduced ability remains a few months after childbirth $(8,20)$.

Many investigations have been done on the factors influencing LBP. However, only a few have assessed influential factors on severity and disability due to LBP. Our results showed meaningful associations of increased gestational age, increased number of parity, and previous history of LBP with disability due to LBP (ODI). This study indicated that maximum pain happened in the second trimester and disability increased with gestational age, as the maximum mean disability (ODI) was in the third trimester of pregnancy. Our results are consistent with that of Mohseni-Bandpei et al (1). Mohseni-Bandpei and colleagues, in a study similar to this study, found a linear tendency between gestational age and disability (1).

In fact, in later trimesters, women tend to limit their activities to taking care of their foetuses. Due to the increased size of the abdomen, they avoid activities that intensify LBP, such as bending forward to pick up objects. Therefore, they may experience less pain due to more limitations and restrictions in movements. This might be a reason for the maximum pain in the second trimester and maximum disability in daily activities in the third trimester, as shown in this study and some others (1).

This study showed that another factor that significantly affected disability was parity. Women with more parity experienced more disability and their disability increased by 7.06 as per gestation, as in the other studies $(1,3,13)$.

The reason might be the weakening of lumbar muscles due to postural changes in pregnancy. Joint mobility has been reported to increase in pregnant multiparous women (21). The other important factor is previous history of LBP. In earlier studies, prior history of LBP and pregnancyassociated pelvic girdle pain were shown to be powerful predictors of pregnancy- associated back/pelvic pain and also, pre-pregnancy LBP was recognized as a risk factor for disability after childbirth $(3,13,22)$. Another factor that seems to be important is body mass index (BMI). Although we did not find any meaningful association between BMI and disability due to LBP, women with higher BMI had more disabilities. Based on pairwise comparisons between groups (Tukey test), in BMI higher than 30, the average ODI was significantly higher than that in BMI lower than 20. However, there is controversy on the role of BMI in back pain and related disabilities $(2,13)$. Another factor that seems to be important is sports. We found that those who did not exercise during pregnancy had more disability and less intensity compared to those who exercised during pregnancy, but this difference was not significant. Garshasbi et al concluded that exercise was effective in reducing LBP (23). A review study conducted by 
Hassanabadi and colleagues (24) concluded that studies in the field were very diffuse and because of various designs of these studies, the impact of an exercise programme on the improvement of LBP during pregnancy could not be definitively determined. Overall, they indicated that exercise had established effects on reducing back pain during pregnancy $(1,24)$. In this study, no relationship was found between disability and work, mode of delivery, and lumbar anaesthesia. These results are in accordance with those of the other studies (25-27).

\section{Conclusions}

In this study, nearly $69 \%$ of the women reported LBP at the time of inspection. The disability was moderate in the majority of cases (44\%), and severe to very severe in one-third (31\%) of the cases. Women with more disability due to LBP often had LBP in their past history, a greater number of previous pregnancies, and higher gestational ages.

\section{Conflict of Interests}

Authors declare that they have no conflict of interests.

\section{Ethical Issues}

This study was approved by the Local Ethics Committee of Shahed University (code of ethics: 41/181321).

\section{Financial Support}

This study was financially supported by Medical School, Shahed University, Tehran, Iran.

\section{Acknowledgement}

We would like to thank the personnel of Mostafa Khomeini Prenatal Clinic for their cooperation.

\section{References}

1. Mohseni-Bandpei MA, Fakhri M, Ahmad-Shirvani M, et al. Low back pain in 1,100 Iranian pregnant women: prevalence and risk factors. Spine J. 2009;9(10):795-801. doi:10.1016/j.spinee.2009.05.012

2. Wu WH, Meijer OG, Uegaki K, et al. Pregnancyrelated pelvic girdle pain (PPP), I: Terminology, clinical presentation, and prevalence. Eur Spine J. 2004;13(7):575589. doi:10.1007/s00586-003-0615-y

3. Mens JM, Huis YH, Pool-Goudzwaard A. Severity of signs and symptoms in lumbopelvic pain during pregnancy. Manual therapy. 2012;17(2):175-9. doi: 10.1016/j. math.2011.12.012

4. Noren L, Ostgaard S, Johansson G, Ostgaard HC. Lumbar back and posterior pelvic pain during pregnancy: a 3-year follow-up. Eur Spine J. 2002;11(3):267-271. doi:10.1007/ s00586-001-0357-7

5. Mota MJ, Cardoso M, Carvalho A, Marques A, Sa-Couto P, Demain S. Women's experiences of low back pain during pregnancy. J Back Musculoskelet Rehabil. 2015;28(2):351357. doi:10.3233/bmr-140527

6. Marnach ML, Ramin KD, Ramsey PS, Song SW, Stensland
JJ, An KN. Characterization of the relationship between joint laxity and maternal hormones in pregnancy. Obstet Gynecol. 2003;101(2):331-335.

7. Cunnigham F, Gant N, Leveno K, Gilstrap III L, Hauth J, Wenstrom K. Willams obstetrics. 23rd ed. New York: McGraw-Hill; 2010.

8. Malmqvist S, Kjaermann I, Andersen K, Okland I, Bronnick K, Larsen JP. Prevalence of low back and pelvic pain during pregnancy in a Norwegian population. J Manipulative Physiol Ther. 2012;35(4):272-278. doi:10.1016/j. jmpt.2012.04.004

9. Olsson C, Lena NW. Health-related quality of life and physical ability among pregnant women with and without back pain in late pregnancy. Acta Obstet Gynecol Scand. 2004;83(4):351-357.

10. Stafne SN, Salvesen KA, Romundstad PR, Stuge B, Morkved S. Does regular exercise during pregnancy influence lumbopelvic pain? A randomized controlled trial. Acta Obstet Gynecol Scand. 2012;91(5):552-559. doi:10.1111/ j.1600-0412.2012.01382.x

11. Mogren I. Perceived health, sick leave, psychosocial situation, and sexual life in women with low-back pain and pelvic pain during pregnancy. Acta Obstet Gynecol Scand. 2006;85(6):647-656. doi:10.1080/00016340600607297

12. Stapleton DB, MacLennan AH, Kristiansson P. The prevalence of recalled low back pain during and after pregnancy: a South Australian population survey. Aust N Z J Obstet Gynaecol. 2002;42(5):482-485. doi:10.1111/j.00048666.2002.00482.x

13. Charpentier K, Leboucher J, Lawani M, Toumi H, Dumas GA, Pinti A. Back pain during pregnancy and living conditions: a comparison between Beninese and Canadian women. Ann Phys Rehabil Med. 2012;55(3):148-159. doi:10.1016/j.rehab.2012.02.003

14. Mousavi SJ, Parnianpour M, Mehdian H, Montazeri A, Mobini B. The Oswestry Disability Index, the RolandMorris Disability Questionnaire, and the Quebec Back Pain Disability Scale: translation and validation studies of the Iranian versions. Spine (Phila Pa 1976). 2006;31(14):E454459. doi:10.1097/01.brs.0000222141.61424.f7

15. Ando F, Ohashi K. Using the posterior pelvic pain provocation test in pregnant Japanese women. Nurs Health Sci. 2009;11(1):3-9. doi:10.1111/j.1442-2018.2008.00406.x

16. Goli S, Shayanmanesh M, Moeinimehr M. Low back pain and pelvic pain during pregnancy: prevalence and risk factors. Health System Research. 2014; 10(2):226-34.

17. Adair LD, Skaggs C, Mason LA, Williams T. Low Back Pain Disability During Pregnancy Evaluated by Oswestry. McCallie Chiropractic \& Rehab. 2015;2(3):10-4.

18. Madeira HG, Garcia JB, Lima MV, Serra HO. [Disability and factors associated with gestational low back pain]. Rev Bras Ginecol Obstet. 2013;35(12):541-548. doi:10.1590/ S0100-72032013001200003

19. Pierce H, Homer CS, Dahlen HG, King J. Pregnancy-related lumbopelvic pain: listening to Australian women. Nurs Res Pract. 2012;2012:387428. doi:10.1155/2012/387428

20. Gutke A, Lundberg M, Ostgaard HC, Oberg B. Impact of postpartum lumbopelvic pain on disability, pain intensity, health-related quality of life, activity level, kinesiophobia, and depressive symptoms. Eur Spine J. 2011;20(3):440-448. 
doi:10.1007/s00586-010-1487-6

21. Bjelland EK, Eskild A, Johansen R, Eberhard-Gran M. Pelvic girdle pain in pregnancy: the impact of parity. Am J Obstet Gynecol. 2010;203(2):146.e141-146. doi:10.1016/j. ajog.2010.03.040

22. Ansari NN, Hasson S, Naghdi S, Keyhani S, Jalaie S. Low back pain during pregnancy in Iranian women: Prevalence and risk factors. Physiother Theory Pract. 2010;26(1):40-48. doi:10.3109/09593980802664968

23. Garshasbi A, Faghih Zadeh S. The effect of exercise on the intensity of low back pain in pregnant women. Int J Gynaecol Obstet. 2005;88(3):271-275. doi:10.1016/j. ijgo.2004.12.001

24. Hasanabadi H, Tara F, Bahr N. The effects of exercise on back pain during pregnancy: A review article. Iranian Journal of Obstetrics and Gynecology. 2014;17(3):16-28.

25. Ghadarie F AJ, Mohsanie Band-Pay MA. Prevalence and Related factors of muscular pain during pregnancy. Health and Care journal. 2011;14(3):55-62.

26. Sedighi A, Moradi A, Ostad- Rahimi AR, Lotfinia I, Zarghami NA. Prevalence of low back pain in women of fertility age in Tabriz and related factors. Medical Journal of Tabriz University of Medical Science. 2008;30(2):87-91.

27. Abbasi S, Hamid M, Ahmed Z, Nawaz FH. Prevalence of low back pain experienced after delivery with and without epidural analgesia: A non-randomised prospective direct and telephonic survey. Indian J Anaesth. 2014;58(2):143148. doi:10.4103/0019-5049.130814

(C) 2018 The Author (s); This is an open-access article distributed under the terms of the Creative Commons Attribution License (http://creativecommons.org/licenses/by/4.0), which permits unrestricted use, distribution, and reproduction in any medium, provided the original work is properly cited. 